DOI: 10.1515/auseur-2017-0005

\title{
Adaptation Strategies to Turkish Society of Europeans Married to Turkish Citizens
}

\author{
Nevena GOJKOVIC TURUNZ \\ freelance researcher \\ Gojkovic.nena@gmail.com
}

\begin{abstract}
Accelerated and increasingly complex patterns of international migration are correlated with the emergence of various types of transnational families and an ever-rising number of culturally and ethnically mixed couples. Once a typical emigration country, Turkey has recently been established as a transit and receiving society, where numerous Europeans settle due to emotional ties with Turkish citizens. This paper is based on a qualitative study of 10 mixed European-Turkish families based in Istanbul, carried out through in-depth interviews. The paper is divided into three parts. First, it examines the social characteristics of the research participants. Second, it analyses the reactions of family and friends to the mixed relationship. Third, it discusses four adaptation strategies of foreign partners to Turkish society - namely, integration, assimilation, separation, and marginalization.
\end{abstract}

Keywords: mixed couples, adaptation strategies

\section{Turkish Migratory Field: an Overview}

During the last two centuries, the territory of modern Turkey has been a space of dynamic population movements, and it has been characterized by both mass influx and mass outflow of people. The high influx of Muslims from the Caucasus, Crimea, and the Balkans into Anatolia started at the end of the $18^{\text {th }}$ century, accelerated in the $19^{\text {th }}$, and continued throughout the first decades of the $20^{\text {th }}$ century. Russian advancement to Crimea and the Caucasus caused mass migratory movements of Tatars and Circassians to the Ottoman Empire. Akgündüz cites the estimated number of 1,800,000 Tatars and approximately the same number of Circassians who found a shelter in today's Turkey between the mid$19^{\text {th }}$ century and 1922 (Akgündüz 1998: 98). At the same time, the establishment of nation-states in the Balkans as well as the two Balkan wars in 1912 and 1913 caused a large-scale migration of the Balkan Muslims to the mainland of the Ottoman Empire. According to Akgündüz, 'from 1793 to 1913, some 5-7 million 
Muslims immigrated into the Ottoman lands' altogether (Akgündüz 1998: 100). In addition, Ülker cites 800,000 immigrants coming from the Balkans between 1923 and 1939 (Ülker 2007).

However, as Tolay reminds us, "in the Turkish imagination, they were not migrants settling in a "foreign" country; they were not "foreigners" migrating to Turkey. Rather, they were considered as "Turks" "returning" to their "homeland" (even though hardly any of them had ever lived in Turkey and most of them had only a remote knowledge of the Turkish language)' (Tolay 2012: 4). In general, they were quickly and thoroughly assimilated in the course of the nation-state building.

According to Ülker, the rapid assimilation was conducted in two ways. First, the non-Turkish-speaking Muslims were settled in Anatolia among the Turkishspeaking population. Second, the Turkish-speaking immigrants were settled in the Kurdish areas and hence changed the demographic structure there (Ülker 2007). The official state policy was undoubtedly assimilatory. As a result, the immigrants were prevented from cherishing their language and culture and were 'Turkified'. Since the establishment of the Republic, the Turkish nation has been based on what Kaya labels as 'the Sunni-Muslim-Turk trinity' (Kaya 2012: 91), and the incorporation of immigrants followed the same logic.

Conversely, work-related emigration from Turkey was typical in the 1960s and 1970s. Millions of Turks left the country as a result of the recruitment agreements that Turkey had signed with various Western European countries, which lacked a labour force to sustain their post-war economic boom. After the recruitment process was stopped in 1975, the influx of Turks continued through family reunification. In addition, in the aftermath of the Turkish coup d'état in 1980, the guest workers were joined by political refugees.

In the last several decades, the sharp distinction between the sending countries of the poor global South and the receiving countries of the rich North has become blurred. In addition to being an established country of emigration, Turkey started to receive transiting, temporary, and permanent immigrants and has developed into a 'diversified migratory field' (Tolay 2012: 2). Concurrently, the emigration to Turkey became a comparatively recent but a proliferating field of research.

Furthermore, the increasingly complex patterns of international migration and higher mobility are also directly correlated with the emergence of various types of spatially dispersed transnational families. As presently many young people have an opportunity to meet potential life partners away from their hometowns and even home countries, there is also an evident trend of a rising number of cross-national couples. Hence, in this paper, I will focus on a particular group of migrants that I refer to as 'love migrants', women and men from Europe, who had settled down in Istanbul due to their emotional ties with Turkish citizens and established a family. In the Turkish context, my work aims to be a contribution to the field by studying this under-researched phenomenon. The paper deals with 
the question that each mixed family needs to answer: 'who are we as a family and where do we stand with regard to our respective societies?' It is divided into three parts and examines a) the social characteristics of the research participants, b) the reactions of family and friends to their relationship, and c) the adaptation strategies of non-Turkish partners to Turkish society.

\section{Methodology}

My research represents an in-depth micro-level study. Thus, the research methodology is qualitative for the reason that the aforementioned research questions can best be answered through exploring and analysing the decisions, experiences, narratives, ideas, emotions, and perceptions of individuals. Mason argues that the usage of in-depth, semi-structured interviews is appropriate when the goal of the research is the 'understanding of depth and complexity in people's situated or contextual accounts and experiences' (Mason 2002: 65).

I conducted interviews in Istanbul in the spring of 2014 with three women from Serbia, one from Poland, Ireland, Russia, and Turkey, one woman from Germany and her two daughters, a Turkish-Italian family (Turkish wife, Italian husband, and two children), and one man from England. According to the research criteria, all the participants live in Turkish/European marriages, have children, and reside in Istanbul or have resided there until recently. Last year, the Turkish/French couple moved to Jamaica, one of the Serbian-Turkish couples settled down in Ankara, and the Russian/Turkish couple moved to Nizhny Novgorod. I reached the participants through personal contacts and by public calls on Facebook pages such as the 'International Women of Istanbul', 'TOMER (Turkish and Foreign Languages Research and Application Centre)', 'Expats of Turkey', and 'Serbs in Istanbul'.

I conducted and recorded interviews in the participants' homes or cafés, each one lasting between 45 minutes and two hours. The interview protocol was linked to several main topics (getting to know each other, reactions of family and friends, adaptation to life in Istanbul, names and religious affiliation of children, teaching of a minority language, experiences of child rearing in a foreign country), rather than based on pre-defined sets of questions. The structure of the interviews was flexible due to the different experiences and priorities given to different aspects by the informants. Such an approach allowed the informants to focus on issues most relevant to their own family. For instance, some participants skipped questions about the religious life in their family, whereas others provided lengthy accounts. Subsequently, Itranscribed the interviews and coded them by 'identifying appropriate blocks of text with a particular code' (Campbell et al. 2013: 297) and putting them into the coding scheme. Afterwards, I linked grouped quotations to the relevant theoretical framework and analysed them from the perspective of interpretivism. 


\section{Research Participants: Shared Social Characteristics}

Research participants are middle- and upper-middle-class people from nine different countries (England, France, Germany, Ireland, Italy, Poland, Russia, Turkey, and Serbia). The main criterion for selection was that the non-Turkish participants moved to Turkey primarily because of a relationship with a Turkish citizen. Hence, I purposefully excluded other types of immigrants (i.e. refugees, undocumented immigrants, work immigrants, circular immigrants from postSoviet countries, or Turkish returnees from European countries) from the research. Nonetheless, I did not intentionally leave out people from lower or upper classes. Rather, they never replied to my public calls on Facebook pages (Serbs in Istanbul, TOMER, Expats of Turkey, and International Women in Istanbul) nor was I able to contact them through personal contacts.

In addition, the similarity within my sample regarding education, previous experiences of living abroad, and international travel is noteworthy. Among my research participants, only one person (a German wife, Caroline) possesses an apprenticeship degree, whereas all the others hold at least a bachelor's diploma, including one professor at a university and a Ph.D. candidate. The most common profession for female participants (six out of ten) is a professor of language and literature, which is in line with the argument that linguistic competence significantly increases cross-national matching opportunities. Garrido and Olmos identify the mastery of the language as a crucial cultural resource which 'increases opportunities for contact and communication' (Garrido-Olmos 2014: 303). On the other hand, male participants are typically engineers and thus ready to work in different countries.

From the ten interviewed couples, only one had met in the city where both partners settled permanently. Caroline (German) and her husband Mehmed (Turkish) attended the same high school in a small German town at the end of the 1970s. This story is illustrative of a mixed marriage between a wife of a majority ethnic group and an immigrant man in the context of German guest worker migration. Mehmed's parents were low-skilled manual workers from rural Turkey. They came to Germany during the first wave of labour migration from Turkey and never succeeded in mastering the German language. Mehmed, thanks to the effort and encouragement of a primary school teacher, attended a high school, which paved him a road to the university. As the only Turk in the class, he developed close friendships with ethnic Germans, fully mastered the language, and became part of mainstream German society. An unintended consequence of his educational success was the alienation from fellow conationals in Germany. In turn, the detachment from Mehmed's ethnic, religious, and linguistic background critically influenced the raising of their children in an exclusively mono-cultural (German) manner. 
According to the analysis of Furtado and Theodoropoulos on how the education of immigrants affects their ethnic attachment, 'the relationship between education and ethnic attachment depends on the average skill level of a person's ethnic group as well as his nativity, age at arrival, and race' (FurtadoTheodoropoulos 2008: 2). When Mehmed had grown up and eventually embarked on university studies, the vast majority of Turks in Germany were low-skilled manual workers. The discrepancy between him and the Turkish community with regard to education intersects with his nativity (all German friends) and his arrival to Germany at an early age, which enabled him to be proficient in German, explaining his preference for marrying a German.

In all other instances, husbands and wives are significantly younger than Caroline and Mehmed. Seven other couples are in their 30s, whereas two couples are in their 40s (Didem is Turkish and Alberto Italian; Richard is English and Ayşe Turkish). Hence, the other couples got to know each other not in a context of classical work migration from poor global South to the rich global North but in the circumstances involving international travel, studies abroad, or temporary high-skilled positions in a foreign country. Education, especially language learning, proves to be a critical factor in cross-national mating.

Furtado argues that education affects intermarriage through three mechanisms. These are a) the cultural adaptability effect, b) the enclave effect, and c) the assortative matching effect. First, 'the cultural adaptability effect suggests educated people are better able to adapt to different customs and cultures' (Furtado-Theodoropoulos 2008: 3). Second, 'the enclave effect suggests that educated immigrants are more likely to move out of their ethnic enclaves because, for example, they have larger geographic labor markets" (FurtadoTheodoropoulos 2008: 3). Correspondingly, the educated participants in my research had opportunities to study abroad and thus to meet partners of different ethnic origin. Third, 'the assortative matching effect posits that marriage surplus increases when education levels of husband and wife are similar. This implies that given a costly search process, educated immigrants may be willing to substitute similarities in ethnicity for similarities in education' (Furtado-Theodoropoulos 2008: 3). Moreover, international business is one more favourable context for cross-national matching. Also, given the rise in international travel, it is not surprising that one couple came together in a tourist context.

Furthermore, one important characteristic of the sample is their overall secularism. Only Caroline, the German woman, reported being an observant Protestant, whereas her husband is not religious. Besides that, there is also a religious Turkish-Serbian couple. Both husband and wife are pious; one does not prevent the other from observing their religious obligations. This finding is in line with the research, demonstrating that religious groups act as gatekeepers. The empirical research of Lucassen and Laarman (2009) on intermarriage patterns 
in the Netherlands, Belgium, England, France, and Germany in the post-WWII period showed that "migrants whose faith has no tradition in Western Europe intermarry at a much lower rate than the ones with religious backgrounds that correspond to those common in the country of settlement' (Lucassen-Laarman 2009: 1). The authors point out that people of Hindu and Muslim backgrounds are the least likely to intermarry.

Likewise, Carol studied attitudes toward the intermarriage of the native population in Belgium, Great Britain, Germany, and Switzerland, and immigrants from ex-Yugoslavia, Morocco, Turkey, and Pakistan. The results show that immigrants coming from countries with higher degrees of religiosity (Pakistan and Morocco) are less likely to approve intermarriage than immigrants from exYugoslavia and Turkey. Carol concludes that 'religious identity among migrants and practice among both natives and migrants are associated with reluctance to intermarry' (Carol 2013: 67).

Alike, Dribe and Lundh examined intermarriage for 138 immigrant groups in Sweden between 1990 and 2005. According to their results, the intermarriage rate varies from below 5 percent in some groups (immigrants from the Middle East and Africa) to over 70 percent for the others (Western Europe and North America). The authors argue that cultural factors (values, religion, and language) are crucial for understanding the phenomena. They draw the conclusion that 'the tendency to religious endogamy is the highest for immigrant groups from countries with a high level of religiosity, especially from Muslim countries' (Alike et al. 2011: 320).

To summarize, the shared characteristics of my research participants are higher education, belonging to the middle-class, loose adherence to a religious in-group, previous experiences of living abroad and international travel, and mastery of foreign languages. In all cases, correspondence in education level, socioeconomic status, and lifestyle supersedes ethnic, cultural, and religious differences. This finding corresponds with the assumption of Blau, Beeker, and Fitzpatrick that people, in general, have preferences for in-group marriage; however, 'if various social affiliations intersect, the rates of intermarriage would depend on the degree to which many social affiliations intersect' (Blau et al. 1984: 600).

When discussing homophily - 'the principle that a contact between similar people occurs at a higher rate' -, McPherson, Smith-Lovin, and Cook, following Lazarsfeld and Merton, distinguish between ascribed status homophily and acquired status homophily. 'Status homophily includes the major sociodemographic dimensions that stratify society - ascribed characteristics like race, ethnicity, sex, or age, and acquired characteristics like religion, education, occupation, or behavior patterns' (McPherson et al. 2011: 419). Besides, religion is typically inherited from the family. The couples in this study demonstrate a high degree of acquired status homophily. Furthermore, 'value homophily 
includes the wide variety of internal states presumed to shape our orientation toward future behavior' (McPherson et al. 2011: 419). Correspondingly, Garrido and Olmos argue that socioeconomic and cultural preferences are critical for interethnic matching. Cultural resources which 'include values, opinions, lifestyles or views of the world, and the mastery of the language' are particularly important (Garrido-Olmos 2014: 303). Kalmijn emphasizes the role of cultural similarity in establishing and maintaining close long-term relationships:

The similarity of values and opinions lead to the mutual confirmation of each other's behaviour, and worldviews, the similarity of taste is attractive because it enlarges opportunities to participate in joint activities, and the similarity of knowledge creates a common basis for conversation, which enhances mutual understanding (Kalmijn 1998: 399).

Participants frequently emphasize shared values and lifestyles: 'We were always very liberal, free-minded, we did not need to reach an agreement on main values because we believe in universal values'. ${ }^{1}$ In addition, all participants present themselves as open-minded, liberal, and cosmopolitan. Caroline claims that 'although my family was conservative, I grew up to be open-minded'. ${ }^{2}$ Similarly, Defne argues that 'my family is not religious or nationalist at all, and we know foreigners'. ${ }^{3}$ Additionally, Aleksandra problematizes the existence of national groups: 'For me, nations are something completely artificial, I don't believe in borders. Not all people are the same, but that diversity makes this world wonderful. Borders should not be walls but open; let's get to know each other'. ${ }^{4}$

The self-reported personal characteristics of the research participants correspond with the claim of Benet-Martínez and Haritatas that certain cognitive and affective traits facilitate the development of bicultural identity. The authors point out that qualities such as 'tolerance of and interest in new values and lifestyles' (Benet-Martínez-Haritatas 2005: 1022), 'emotional stability (i.e. resilience, flexibility)' (Benet-Martínez-Haritatas 2005: 1022), 'extraversion (i.e. sociability and expressiveness)' (Benet-Martínez-Haritatas 2005: 1023), and 'agreeableness (i.e. empathy and warmth)' (Benet-Martínez-Haritatas 2005: 1023) are crucial for being comfortable in two social and cultural settings. Among my research participants, the influence of personal characteristics is twofold: they influence both the initiation of a relationship with a foreigner and, even more importantly, the attitude toward the partner's country and the adaptation strategies, as will be shown subsequently.

Finally, I argue that my research participants possess mobility capital, defined as 'the knowledge amassed through international mobility that increases one's potential

1 Didem-Alberto, personal communication, 27 May 2014.

2 Caroline, personal communication, 1 June 2014.

3 Defne, personal communication, 10 June 2014.

4 Aleksandra, personal communication, 6 June 2014. 
ability to move abroad and assimilate into national and transnational structures' (Scott-Cartledge 2009: 76). Furthermore, 'it may relate to the modification of the existing forms of capital (social, cultural, linguistic, economic, or human) or it may involve the acquisition of a new type of capital resource altogether (Scott-Cartledge 2009: 76). Section 5 will demonstrate the role of participants' social characteristics and different types of capital impact adaptation strategies to Turkish society.

\section{Initial Reactions and the Acceptance of the Relationship}

Although the rate of mixed marriages is increasing, and marriages based on love are the norm in Western societies, the majority of people still marry someone from the same social, ethnic, and religious circle. Attitudes towards mixed intimate relationships greatly vary and in extreme cases lead to violence. Smart and Shipman criticize the individualization thesis advocated primarily by Bauman and Beck and a selection of a partner as a 'free' choice of an individual. Rather, they argue that the majority of people still take into account the preferences of their parents and thus marry a person sharing their ethnicity and religion. They claim, on the basis of empirical research, that the selection of a partner based on love does not correlate with 'rejecting an entire tradition and other family and kinship obligations' (Smart-Shipman 2004: 12). Rather, people in mixed marriages, combine 'elements of individualization with a deep commitment to other aspects of traditional cultures' (Smart-Shipman 2004: 14).

People who independently choose out-group partners usually still want the support of their parents. This corresponds with Campbell and Wright's argument, according to which the 'adjustment to intercultural marriage is related to the level of acceptance the couple experiences in their circle of friends, at work, in neighborhoods, and in other social environments outside the family' (CampbellWright 2009: 859). In this research, the first obstacle that cross-national couples face is the overall adverse reactions of their parents and friends.

All participants report minor objections on the part of their parents, such as a mild scepticism ('Are you sure?' Kassia, Tanja), referring to a movie 'Not Without My Daughter', depicting an American lady trying to escape from Iran (Kassia, Clare), and subtle discomfort: 'of course they were uncomfortable. My mother was a bit upset. Both mothers. Also, my father was not happy. But they never told us no. ${ }^{5}$ Nonetheless, in a few cases, parental objection was stronger. Caroline's German parents 'did not want a Muslim son-in-law, and they show it openly, until this day'. ${ }^{6}$ They set clear and impermeable ethnic (native Germans

$5 \quad$ Didem, personal communication, 27 May 2014.

6 Caroline, personal communication, 1 June 2014. 
vs immigrant Turks), religious (Christian vs Muslim), and class boundaries (the middle classes vs low-skilled workers). They met Mehmed's parents only once and never welcomed him into their home. On the other hand, they eagerly accepted their first-born daughter and raised her themselves to allow Caroline to finish her studies. To summarize, they refused Mehmed in spite of his full assimilation into German society and a rupture with Islam but eventually resorted to a strategy of taking over the responsibility of the children and raising them in a pure German and Christian setting.

Furthermore, only one set of parents had openly tried to stop the relationship. From Richard's long account, it is possible to extrapolate how significant the moral conventions are for opposing an out-group union:

We had a great difficulty. I was married before, and I have children from my previous marriage. And that's no, no. Anytime I would have time off, I would travel to Turkey to try to get the permission of her parents for our marriage. During many visits, they would not even see me; they would just tell her she should finish with me. Eventually, my wife fell in some kind of depression. She wanted to be with me, I wanted to be with her, but her parents were against it, and in the end, I think her parents said ok. It took them a long time, and they love me now, but to this day I have to keep my life very separate. My in-laws don't acknowledge that my children exist. Even my daughter does not know that she has a brother and a sister. I used to have to deny my own children to people here. It is a lot of mental cruelty to me. It's horrible! ${ }^{7}$

Faced with their daughter's firm decisiveness to marry an Englishman, they finally approved it, although with an implicit condition to hide relevant information about his previous life, which violates their moral code and may provoke condemnation from their social circle. While studying parental reactions on intimate out-group relationships within the Turkish immigrant community in the Netherlands, Munniksma et al. developed the concept of 'family reputation vulnerability' (Munniksma et al. 2011: 576). It refers to 'the extent to which parents think that the behavior of their child affects the reputation of the family within their ethnic community' (Munniksma et al. 2011: 576), and in 'cultures that put a high value on conformity and family integrity it is more important for parents that their children do not deviate from in-group norms' (Munniksma et al. 2011: 576). In this case, the family reputation is preserved by not revealing the personal history of the son-in-law.

Walter \& Cookie White examine prejudices and stereotypes towards ethnic groups through integrated threat theory, which distinguishes four types of subjectively perceived threats that an out-group represents towards the in-group:

7 Richard, personal communication, 29 May 2014. 
realistic threats, intergroup anxiety, negative stereotypes, and symbolic threats (Walter-Cookie White 2000: 25). First, realistic threats are 'threats to the very existence of the in-group (e.g., through warfare), threats to the political and economic power of the in-group, and threats to the physical or material wellbeing of the in-group or its members (e.g., their health)' (Walter-Cookie White 2000: 25). Second, intergroup anxiety refers to the anxiety the members of one group may feel when in the presence of members of the other group - for instance, discomfort, shame, and embarrassment (Walter-Cookie White 2000: 27). Third, the negative stereotypes lead members of one group to expect certain negative behaviour from the members of a certain group. In Walter \& Cookie White's words: 'to the extent that the expectations are negative, conflictual or unpleasant interactions are likely to be anticipated' (Walter-Cookie White 2000: 28). Fourth, the symbolic threats are 'threats to the worldview' (Walter-Cookie White 2000: 25 ) and involve 'perceived group differences in morals, values, standards, beliefs, and attitudes' (Walter-Cookie White 2000: 25). Most importantly, symbolic threats are based on the in-group belief 'in the moral rightness of its system of values' (Walter-Cookie White 2000: 25). The most relevant for my research are the negative stereotypes and symbolic threats.

The gender-based stereotypes against Turkish men as womanizers or oppressive towards their wives at the beginning of a relationship are frequently reported. For families with Christian backgrounds, the perceived treatment of women in Turkey presents a major threat, and it is a consequence of negative stereotypes toward Turkish men. The fear based on negative stereotypes is exemplified in Clare's account: 'My sister was very frightened; maybe I would be also if she married a Turk. There are many misconceptions of what Muslim culture is like. It is a lack of knowledge, it boils down to ignorance, and, in a way, you cannot blame them.'

Moreover, as Sanja claims, the majority of friends' reactions can be summarized as 'Please, don't tell me you were dating a Turk? Long-distance? So, you really think he is not cheating on you?'9 Likewise, Defne (Turkish) reports her first encounters with a husband's family and friends:

He is coming from the south of France, from a small village. They have never seen a Turkish person before. They were telling me, "but you cannot dress like that in Turkey, can you?' when I was wearing short sleeves. Also, whenever we went to visit someone new, they would ask Jerome if I drink alcohol and eat pork. When they came to Istanbul for the wedding, they realized that Turkey is not a country like Iran at all. They were surprised to see it, and they completely changed their ideas about Turkey. ${ }^{10}$

8 Clare, personal communication, 2 June 2014.

9 Sanja, personal communication, 8 February 2014.

10 Defne, personal communication, 10 June 2014. 
However, the prejudices against Turkish men diminish once a close contact is established. It corresponds to Kalmijn's argument that intermarriages influence transformations of negative attitudes towards other groups. According to Kalmijn:

Interaction gives people an opportunity to realize the individual variety among the members of another group and in doing so, it may ultimately weaken their prejudices and stereotypes. Because intermarriage often connects the social networks of the two spouses, this applies to a range of out-group members and not just to the immediate partners (Kalmijn 1998: 396).

Furthermore, it is intimately important for Europeans that their Turkish family is not 'traditional'. 'Traditional' Turkey is widely imagined as conservative, backward, or, to be more precise, as an antithesis to Europe and its culture. When asked about the Turkish in-laws, the majority of participants began their story by stating how modern and secular they are. Modernity and secularism are outlined as factors which enable communication and ensure a harmonious relationship. The most common strategy is to distance a husband's family from Islam. ('His family is modern. They are secular. There is no Ramadan. They don't pray. And they are from Istanbul; I don't think I would go somewhere in the East.') ${ }^{11}$

Likewise, Sanja (Serbian) simultaneously emphasizes a husband's noncomplying attitude and autonomy by challenging the norms and authorities, on the one hand, and, on the other hand, how progressive his parents are: 'For me, the greatest difference between Serbs and Turks is that here non-married couples cannot stay in the same house during the night. But we stayed together when we were not married, and we even went to his parents in Adana'. ${ }^{12}$ On the contrary, no one attempted to inscribe positive characteristics to the European counterparts, as if their 'modernity' is taken for granted. The participants' narratives echo internalized Eurocentrism, in which Turkey is yet to reach full 'modernity'. However, by insisting on the 'modernity' of the Turkish family, men and women from Europe negotiate and transform symbolic boundaries between them (as the Turks, Muslims, Eastern) and us (Western, secular, modern).

Moreover, not only foreign but also Turkish participants underline the modern outlook of their families: 'You know, I come from a family that is not nationalistic or religious at all. And we know foreigners. ${ }^{13}$ What is more, Didem links religion to the rural origins of her mother by saying 'My parents were not religious. Actually, they never practised it. My father was even quite against religion, I would say. Only sometimes my mother is religious because she is coming from the Anatolian side. ${ }^{14}$

11 Kassia, personal communication, 4 June 2014.

12 Sanja, personal communication, 8 February 2014.

13 Defne, personal communication, 10 June 2014.

14 Didem, personal communication, 27 May 2014. 
Didem's perception reflects the Turkish urban secularist discourse. In this discourse constructed by the Republican elites, as explained by Demiralp, pious Muslims are depicted as provincial, lower-class, even different in physical appearance, with their skin colour being darker than that of their urban counterparts. The internal distinction between Islamists and secularists as well as 'black' Turks and 'white' Turks reproduces the Orientalist Western view of Turkey. As Demiralp argues, for the Republican elites of the Turkish Republic, "Islam became a heuristic or a mental short-cut to describe the "primitive" rural other, and secularism defined the way to Western modernity and civilization' (Demiralp 2012: 514).

Furthermore, the perceived lack of morality of the Western world is threatening for Muslim families. In general, the grandparents are the most afraid that their cultural traits, including religious beliefs, will not be transmitted to their grandchildren. However, if they get a warranty that grandchildren will learn their language and be versed in their customs, the objection to cross-cultural marriage ceases to exist.

Additionally, my research confirms a gender-differentiated attitude towards mixed marriage. According to Islamic religious law, a Muslim man is permitted to marry a non-Muslim woman (Christian and Jewish), whereas the opposite is not allowed. Cila and Lalonde argue that although women are primary caregivers and 'the carriers of cultural and religious continuity for future generations' (CilaLalonde 2014: 359), there is a concern that if a woman is married to a non-Muslim, she would not be allowed to raise her children in Islam. On the other hand, a Muslim man would not face it, 'given the Islamic tradition of the father having the final say in how children are raised' (Peek 2006, as qtd in Cila-Lalonde 2014: 359). Therefore, the intergenerational transmission of religion is ensured when a Muslim man marries a non-Muslim woman, at least at the theoretical level.

The only highly religious Muslim family in the sample did not object to a Serbian Orthodox Christian daughter-in-law. Aleksandra (Serbian) reported a wonderful reaction from Umut's parents, although she anticipated their disagreement, as she is not Turkish and Muslim. What was important for Umut's family was to ensure the intergenerational transmission of Islam. As it was secured by Aleksandra's agreement to raise the children in 'a Muslim spirit', a potential basis for objecting to their marriage ceased to exist.

Similarly, Caroline reported how supportive her in-laws, low-skilled Turkish immigrants in Germany were: 'Certainly they expected to have Turkish gelin. ${ }^{15}$ But they accepted me immediately. They only had this one son, and they realized that our relationship was good for him. I pushed him at school; I pushed him in the university. They saw it would do him good' ${ }^{16}$ In Caroline's case,

15 Bride.

16 Caroline, personal communication, 1 June 2014. 
Mehmed's parents recognized the advantages of marriage with a native German. It corresponds with Remennick's understanding that marriage to a native is 'a guide to a new society, facilitating both cultural adjustment and practical matters' (Remennick 2009: 725).

On the other hand, seemingly secular families, such as the family of Richard's wife, fiercely objected a Christian son-in-law, which actually corresponds to the Islamic tradition. Their relationship with Richard greatly improved upon his acceptance to register a daughter in the Turkish population office as a Muslim, albeit he finds it strange: 'She is registered as Islam. She is unusual because they should take the father's religion, but it is easier for me because of the family. Although I am a Christian.' ${ }^{17}$ The Turkish family managed in assuring, at least, the formal transmission of religion.

As reported by the research participants, the main reasons for objections to cross-national marriage in this research can be summarized as moral concerns, in the sense of different moral codes (such as in Richard's case, whose previous marriage and children presented a moral obstacle) and the fear of the loss of religion, language, and national identity in subsequent generations. Upon ensuring that children will be familiar with the heritage, in-laws tend to accept the marriage. Transmitting religion is a condition of particular importance for religious people. Mastering a language is an important factor enabling communication with the in-laws and hence leading to acceptance, accompanied with prolonged periods of life together in the same household and, particularly when children are born, respecting each other's heritage.

In this research, each cross-national family is formed despite various degrees of initial refusal by the parents and the suspicion of friends. This is indicative of the individualization process in the societies in question. Didem and Alberto explicitly dismiss their parents' opinion by saying 'what our parents thought never had too much importance for us. But even if they objected, it would be not a problem because we have a very strong bonding with each other. No outsider effect would influence us. ${ }^{18}$

With the passing of time, generally closer relationships between parents and sons- and daughters-in-law develop, attitudes change, and tensions subside. All participants, except the German-Turkish couple, report a significant improvement of mutual relationships despite a tense beginning. Even Richard (English), whose in-laws refused a meeting at first, reported a warm and emotional relation with them, albeit complex and loaded with disagreements.

17 Richard, personal communication, 29 May 2014.

18 Didem and Alberto, personal communication, 27 May 2014. 


\section{Adaptation Strategies to Turkish Society}

Although the assimilation theory in migration studies has been challenged, in recent research intermarriage is still taken as the final assimilation phase. Meng and Gregory (2005) suggest intermarriage is crucial for economic assimilation. As a result of the native partner's assistance in learning the language and the customs of the society, since they provide information about these, and due to their contacts, intermarried immigrants are better off economically than their non-married counterparts. Bisin and Verdier (2000) argue that an individual parent's ability to transmit cultural traits to their children depends on partner choice. In a case where a minority member marries heterogeneously, chances for successful transmissions are limited, and most likely a child will internalize a majority set of cultural traits. For Quian and Lichter, 'intermarriage provides a clear signal that minority group members have adopted cultural patterns of the host or majority population, such as its language and customs, and that they have been absorbed, both economically and politically into mainstream society" (Quian-Lichter 2007: 70).

Scott and Cartledge discuss assimilation in relation to individuals who migrate abroad for emotional reasons. In their view, immigrants belonging to transnational families possess resources enabling the uncomplicated assimilation into the 'host' society. It is their claim that 'few first-generation migrants can be said to have "gone native". Moreover, those that have tend to share one thing in common: they live with a partner born and brought up in the host country' (Scott-Cartledge 2009: 61). In addition, in their argument, women are more likely to be assimilated into their partner's society due to their superior language skills and for the reason that 'national identity/patriotism tends to be a less intense locational tie for women than it is for men' (Scott-Cartledge 2009: 66).

However, Song corrected a widely-held assumption on intermarriage as a final stage in the assimilation process:

So, while intermarriage may be said to herald a form of structural assimilation in terms of one's status and formal inclusion in certain families and social networks and institutions, we cannot assume that minority individuals (or couples) who have intermarried necessarily feel welcomed, or that they 'belong' in many mainstream settings (Song 2009: 341).

Song further argues that a person marrying into a native family will not necessarily receive a warm welcome and social acceptance. In accordance with Song's argument, this research finds a) correlation between the quality of a relationship with Turkish in-laws and adaptation to the Turkish society and b) correlation between the strength of ties with a family of origin and success in 
transmitting cultural heritage. Hence, my research discusses adaptation strategies while taking particularly into consideration the relationship with in-laws.

Berry $(1980,1997,2005,2010)$ developed a theoretical model on four acculturation strategies based on two dimensions: 'the degree to which people wish to maintain their heritage cultures and identities' and 'the degree to which people wish to have contact with those who are outside their group and participate with them in the daily life of the larger society' (Berry 2010: 476). They are labelled as assimilation, integration, separation, and marginalization. Individuals who do not aim to preserve their cultural heritage tend to assimilate fully into the new society. Integration combines the maintenance of culture with participation in larger social networks. 'The marginalization strategy is defined by little possibility or lack of interest in cultural maintenance (often for reasons of enforced cultural loss) and little interest in having relations with others (often for reasons of exclusion or discrimination' (Berry 2010: 476). Furthermore, 'the separation strategy is defined by individuals who place a high value on holding on to their original culture and avoid interaction with members of the new society' (Berry 2010: 476).

When analysing the adaptation strategies of my research participants to Turkish society, I combine Berry's theoretical framework with Tartakovsky's (2011) Acculturation Intensions Model, the study of Burgelt, Morgan, and Pernice (2008) on the effect of pre-migration experiences on adaptation strategies, and Safdar, Lay, and Struther's (2003) study on factors impacting personal well-being in the process of settlement in a foreign country. To conclude, I analyse four basic adaptation strategies (assimilation, integration, marginalization, and separation) through the combination of factors outlined by Berry (2010), Tartakovsky (2011), Burgelt et al. (2008), and Safdar et al. (2003).

Tartakovsky's Acculturation Intensions Model focuses on the factors underlining the preferences for different acculturation strategies. The author defines immigrants' acculturation intentions as 'the immigrants' plans to engage in the specific cultural practices that ensure a desired level of their interaction with people from the host country and from their country of origin, as well as the immigrants' adherence to the corresponding cultural norms and values' (Tartakovsky 2011: 85).

According to this model, the main factor is 'the attitudes towards the country of origin and the receiving country, as it primarily affects the immigrants' intentions to interact with and to accept the norms and values of each society' (Tartakovsky 2011: 86). Secondly, the model takes into account the effect of social norms expressed in the immigration laws, welfare programmes for immigrants, and the policies (Tartakovsky 2011: 87). Third, perceived control over the acculturation process combines 'personal resources needed for acculturation (e.g. the ability to learn languages, openness to new experiences, flexibility, financial 
resources, and job skills) and perceived environmental constraints (e.g. perceived discrimination and social support)' (Tartakovsky 2011: 87). Fourth, the effect of psychological resources on the immigrants refers to specific personality traits. On the one hand, those who are flexible and open to new experiences generally opt for assimilation and integration into the host society. On the other hand, in Tartakovsky's words, 'those who lack the required resources are probably forced to choose acculturation strategies that enable them to interact mostly within their society of origin and avoid interacting with host society (separation and marginalization)' (Tartakovsky 2011: 87). Finally, the effect of environmental constraints refers to the personal experiences of the immigrants. This model 'assumes that the immigrants tend to interact with the members and adhere to the norms and values of society, which they feel is accommodating towards them, while they tend to distance themselves from a society which they perceive as a rejecting [one]' (Tartakovsky 2011: 87).

Furthermore, the study of Burgelt, Morgan, and Pernice (2008) on how premigration experiences impact acculturation strategy is relevant to this research. They identified readiness to migrate, upbringing in an open family with contacts with foreigners, and the degree of the previous travelling (contributing to the ability to manage challenges in a foreign country) as decisive factors for adequate adaptation to the new society. Hence, the research assesses a willingness to move to Turkey and a type of the previous travelling with regard to the chosen adaptation strategy.

Finally, Safdar, Lay, and Struthers (2003) identify several factors important for personal well-being in the course of the acculturation process corresponding to the context of integrated individuals. They particularly emphasize perceived bicultural competence, as 'individuals with high perceived competence have a certain level of knowledge of the host society, are more familiar with its cultural values and beliefs, and have better communication ability' (Safdar et al. 2003: 560561). Additionally, they point out the significance of connectedness to the family. In this research, both connectedness to a family of origin and to the partner's family bear significance. Hence, family allocentrism, as opposed to idiocentrism (focus on the 'unique aspects of self and the division of self from the others' (Safdar et al. 2003: 561)), refers to a sense of strong connectedness to others.

This research finds only one instance of assimilation, Caroline's husband, Mehmed. Although they currently reside in Istanbul, Mehmed was educated and established his career in Germany; they met there, and their children were born and spent the majority of their lives there. As the only ethnic Turk in his high school, at the university, and, through his marriage, with Caroline, his access to formal and informal networks of Germans was smooth. 'He loved playing soccer and he had his soccer friends all being Germans. And being the only Turkish child at school, he was just forced to talk in German. So when we met he would talk 
German even to his siblings. ${ }^{19}$ Despite the presence of his family and numerous co-ethnics, as a result of his upward mobility, he limited his contacts with Germans. His wife, Caroline, explained why as a couple they mostly socialized with Germans from the perspective of class and cultural differences:

We did have Turkish friends at the university, but they were all single, so they would not be relaxed to come to our house. Also, we knew some other Turkish-German couples, but we do not have much contact with them because they are mostly workers. They married some worker German girl to stay there. There was no point in having a relationship with them; there were no topics to talk about; things that we are interested in and things they are interested in are just different. ${ }^{20}$

Mehmed's personal traits (i.e. ability to quickly master the German language, acquire the skills necessary for highly qualified jobs, and easily form friendships with ethnic Germans) coupled with social support (teachers, girlfriend), a tendency to avoid discrimination (a result of a low status of the Turkish community), lack of interest in preserving the Turkish language and culture, and plans for long-term stay in Germany are the factors which contributed to his successful assimilation. The case of Caroline and Mehmed represents an exception among my research participants, and it occurred in the context of Germany. None of the participants reported pressure to assimilate into Turkish society.

The most common adaptation strategy in Turkey is integration. Sanja (Serbia) represents an ideal case of a perfectly integrated person into the Turkish society while simultaneously keeping exceptionally strong ties with Serbia. She holds a BA in Turkish language and literature and works as a translator in Serbian language and as an administrative staff of a famous Turkish hospital, which admits patients from former Yugoslavia for treatment on a daily basis. Her social life in Istanbul is divided between her and her husband's mutual Turkish friends and relatives, several friends from Serbia, and an international group of people (from Romania, Macedonia, Russia, etc.) that she works with at the same hospital. She speaks Serbian, Turkish, and English on a daily basis and communicates with people from numerous countries. She fully participates in the formal and informal networks of the host society and at the same time effectively keeps strong connections with Serbia due to her job and informal networks. Having set the initial boundaries towards the in-laws regarding the upbringing of her child, she cherishes a harmonious relationship with them. She keeps her own 'ethnic private niche' for herself in the diaspora, without involving her husband and son.

19 Caroline, personal communication, 1 June 2014.

20 Caroline, personal communication, 1 June 2014. 
By choosing to specialize in Turkish language and literature prior to meeting her husband, she already showed an interest in Turkey and became proficient in Turkish culture, history, and society. Considering the pre-migration factors of adjustment, she had a cultural and linguistic capital, and a positive attitude towards the partner's country. She is fully culturally and socially competent in both Serbian and Turkish settings, and practises what Steven Vertovec calls 'bifocality' or 'dual orientation' in everyday life (Vertovec 2004: 977).

Besides Sanja (Serbian), the integration strategy is employed by three other women: Aleksandra (Serbian), Kassia (Polish), and Clare (Irish). Common to all of them is their exceptional eagerness to learn the Turkish language and spend prolonged periods of time in the same household with their Turkish in-laws. These proved critical for language acquisition but also for the diminishing of 'acculturation stress' and for the satisfaction with life in Turkey. When a major life event, such as the transition to marriage and parenthood, occurs in an unfamiliar context, a social support is critical for overcoming stress. In fact, the women who had lived with a Turkish mother-in-law once and established a harmonious relationship with her, outlined this experience as an enormous asset enabling successful adaptation.

Professional satisfaction (economic integration) also proves to be an important factor in overall adaptation. Aleksandra and Umut pursue their joint dream of establishing an organic farm, whereas Kassia and Clare work as English teachers. Besides, their social networks are diverse. In addition to cherishing friendly relations with their husbands' families and friends, they have friends within an international community and with fellow nationals.

Only one couple in the sample, Didem (Turkish) and Alberto (Italian), reported a separation from both societies. The essential reason for it was a lack of support by both sets of parents, although they claim they opted voluntarily for what they call multicultural life. The marginalization strategy of Berry was criticized by different authors. For instance, Oudenhoven et al. (2006) argued that immigrant groups do not opt voluntarily to be marginalized, but they are rather forced to accept it. However, the difference between voluntary and forced marginalization is a difference between affluent and low-skilled immigrants (refugees, asylum seekers). Both husband and wife complain about the treatment they receive from their parents: 'her mother, even after 20 years of marriage, when she has a chance, she is staring at me as if I came from some other planet'. ${ }^{21}$ Moreover, in Alberto's words:

Actually, I never had a good relationship with my mother; we always had problems. She is not the type of grandmother who would take care or spend time with grandchildren, either. I always felt I never got any help from her side. And Alberto's mother, she was a typical mother-in-law, jealous, always

21 Didem, personal communication, 27 May 2014. 
interfering, always criticizing, you are not cooking well. But, fortunately, he never took her side. ${ }^{22}$

As a result, Didem and Alberto have created their own private niche and detached themselves from multiple actors in the society. They travel frequently and easily resettle as a family. They are equally distant from their respective Turkish and Italian societies and perceive themselves as a 'multicultural' family with a supra-national identity. Accordingly, their social circle is limited exclusively to the international community. In spite of full proficiency in Turkish and Italian, they still prefer to stay in limited international circles in Turkey and other countries. As Didem recounts their experiences from Pakistan: 'We went out to a very small club only for foreigners, Pakistanis were not allowed to go. Also, we were friends with their high society. Very nice people, always throwing a lot of parties. ${ }^{23}$ Similarly, Alberto observes: 'Foreigners live like on an island in Ankara, so you meet them all the time. We were in Turkey, but still in a multinational environment. ${ }^{24}$ Finally, they openly reject to be associated with their heritages: 'Our friendships are very limited, we cannot be friends with only Turkish or only Italian couples, just with mixed couples' and create a private 'third space'. ${ }^{25}$

Furthermore, if not faced with a welcoming attitude, foreign parents tend to develop an antagonistic position towards the host society and hence opt for a marginalization strategy. It is usually coupled with personal disinterest toward the culture, which is particularly typical for men from countries whose respective cultures are assumed to have a higher value, such as England and France. Hence, they tend to develop a feeling of cultural superiority. Richard moved unwillingly to Turkey due to his wife's illness and was initially confronted with the unwelcoming attitude of the in-laws. Hence, in his view, living in Turkey represents a sacrifice: 'I gave up so much, for example, a great and important job. ${ }^{26} \mathrm{He}$ did not have a previous experience about life abroad nor does he speak a foreign language. It is in line with the empirical finding of Burgelt et al. that 'those participants who traveled less had more limited experiences, knowledge and understanding of themselves and life, and a smaller response repertoire' (Burgelt et al. 2008: 291).

On the other hand, his wife speaks perfect English and has adapted exceptionally well to the English society. He is particularly resentful toward his in-laws and Turkish culture. He claims he does not like anything about Turkish culture or about life in Turkey. His consistent refusal to learn Turkish is in line with the

22 Didem, personal communication, 27 May 2014.

23 Didem, personal communication, 27 May 2014.

24 Alberto, personal communication, 27 May 2014.

25 Didem, personal communication, 27 May 2014.

26 Richard, personal communication, 29 May 2014. 
separation strategy: 'I constantly get harassed, "Why don't you learn Turkish, you've been married for so long..." I met my wife in England; we had been living in England 7 years before we moved to Turkey, and we never needed to speak Turkish. We still speak English to each other. My mother-in-law and father-inlaw, they don't speak English. ${ }^{, 27}$ His attitude towards the Turkish language, 'it is a useless language, face it, English is an international language', ${ }^{28}$ prevents him from mastering it and being competent to fully participate in the society.

Similarly, Jerome (French), an engineer at a large multinational company, who lived twice in Istanbul, where he used to work once and once was between two posts abroad, never attempted to learn Turkish. As in Richard's case, a lack of a common language blocks effective communication with the in-laws, who do not speak English. In both cases, their wives act as mediators, translating back and forth. What is common for Richard and Jerome is that their wives are both having a more positive attitude toward the home country and their temporary stay in Turkey.

The third marginalization case is Tanja (Serbian). In her case, the fact that she had been loosely involved in both sets of families of origin, her lack of proficiency in Turkish, her inability to find a job as a professor of French language and literature, and the refusal of her co-ethnics due to prejudices against Turks, all this contributed to her marginalization. Tanja claims that a group of affluent Serbs living in Istanbul, circles around the consulate, and pilots working for the Turkish Airlines did not accept her due to her marriage to a Turkish man.

Finally, a regression in adaptation can also be possible to occur. Due to her deteriorated relationship with her husband and his parents, Kassia's (Poland) initial contentment with life in Turkey turned into a feeling of resentment. Beforehand fully integrated into Turkish society, she withdrew into separation and became overtly critical of society and culture. The main reason is the perceived lack of help she receives from Turkish in-laws with regard to child rearing.

My mother in-law is not really eager to take care about Doga too much, not as much [as] she should or could. Last year, I had left him with her only for one night, and afterward she said she does not want to take care of him for a night. I left him again last week, and she called me to come and take him. She is 56 and healthy; she does not like kids, to be honest. She is never involved in playing with him. She does not take him to the park. ${ }^{29}$

Her personal disappointment had led to the disappointment with the country and culture. It is coupled with obstacles to visit her home country and the disinterest of her husband in Poland: 'My husband and son have never been

27 Richard, personal communication, 29 May 2014.

28 Richard, personal communication, 29 May 2014.

29 Kassia, personal communication, 4 June 2014. 
to Poland. It is too expensive to go there ${ }^{30}$ as well as a detachment from her family: 'My parents are divorced, and my mom lives in Italy. Also in Poland some families are very close, I just didn't have that experience. ${ }^{31}$

Finally, the findings of this research are in line with the proposed theoretical framework. To summarize, in all four cases of succesful integration, there has been a present eagerness to move to Turkey and prior experiences of international travel, as suggested by Burgelt et al.; personal resources (openness toward Turkish culture, devotion to studying the Turkish language, job skills); social support of Turkish in-laws and a wide group of friends and family connectedness, as well as a lack of perceived discrimination and positive social norms exemplified in an easy access to residence permits. In the case of separation from both societies, the decisive factor is a lack of family connectedness and support that caused the withdrawal of the family unit from both societies. Lastly, in the cases of marginalization, the most important factor is a negative attitude toward Turkey and Turkish culture. As a consequence, these individuals are not likely to learn the Turkish language well enough to participate in social networks.

\section{Conclusions}

My research is in line with Scott's and Cartledge's claim that 'transnational family milieus formed from mixed-nationality relationship migration provide migrants with relatively rapid and direct access to host-country sociocultural networks' (Scott-Cartledge 2009: 66). However, the findings of my research contradict the argument of Scott and Cartledge (2009) that love immigrants, unlike other types of immigrants, are expected to go through 'extreme assimilation'. In the author's empirical research on women from Great Britain married to men from France and vice versa, the participants fully adapted to their partner's society and, for instance, 'all interviewees spoke their partner's language at home and only a minority had brought up their children to be genuinely bilingual' (ScottCartledge 2009: 77).

Quite the contrary, in my research, English is the most common language spoken between Turkish and non-Turkish partners. Even the participants with a good command of Turkish prefer to speak English with their partners. Moreover, all non-Turkish participants successfully taught their native languages to their children, even in the cases of Serbian and Polish, which are not prestigious and widely used languages. Additionally, rather than becoming members solely of their Turkish partner's social networks, the participants tend to maintain relationships with their co-nationals and other foreigners in Turkey. Instead of

30 Kassia, personal communication, 4 June 2014.

31 Kassia, personal communication, 4 June 2014. 
becoming assimilated (with the exception of Caroline's and Mehmed's case), non-Turkish participants preserve strong emotional and social ties with their countries of origin.

All female participants in my research learned the Turkish language. Nonetheless, no one converted to Islam nor changed their dressing style. In my research, the most common strategy is integration, and none of the participants reported a significant social pressure of any kind. I consider several factors to be decisive.

First, the Turkish partners come from overtly secular, middle-class families, and the families in my research reside in urban, secular areas of Istanbul. As a result, the social pressure on non-Turkish women to change and adjust their behaviours and appearance is low. Moreover, the welcoming attitude of Turkish in-laws is most frequently cited as a favourable factor for successful adaptation to Turkish society. Second, the native countries of my research participants are not far from Turkey. Hence, they can easily maintain strong emotional, social, and even professional ties. Besides, when non-Turkish parents approve a marriage with a Turkish citizen and frequently visit Turkey, they provide crucial support. In addition, the participants reported being friends with other Europeans in Istanbul. The networks of ex-pats represent a specific social space for mutual support.

Finally, personal characteristics (i.e. openness and flexibility), consumption of similar cultural goods, and parity in the educational level of non-Turkish and Turkish partners denote shared lifestyles and values and consequently facilitate integration. In other words, the perceived 'cultural' distance between the partners is low. According to Benet-Martínez and Haritatos, the perception of distance or overlap between two cultures impacts acculturation. The authors argue that 'the perceptions that one's two cultures are non-overlapping, dissociated, and distant from one another is related to more learning- and performance-related aspects of the acculturation experience' (Benet-Martínez-Haritatos 2005: 1040). In my research, none of the participants refer to cultural differences with their Turkish partners. Additionally, apart from mastering the Turkish language, the research participants did not need to acquire particular skills for a successful living in the Turkish society and adopt particular social norms and codes of behaviour. 


\section{References}

AKGÜNDÜZ, Ahmet. 1998. Migration to and from Turkey, 1783-1960: Types, Numbers, and Ethnoreligious Dimensions. Journal of Ethnic and Migration Studies 24(1): 97-120.

BENET-MARTÍNEZ, Verónica-HARITATOS, Jana. 2005. Bicultural Identity Integration (BII): Components and Psychosocial Antecedents. Journal of Personality 73(4): 1015-1047.

BERRY, John W. 1997. Immigration, Acculturation, and Adaptation. Applied Psychology: an International Review 46(1): 5-68.

2005. Acculturation: Living Successfully in Two Cultures. International Journal of Intercultural Relations 29: 697-712.

BÜRGELT, Petra T.-MORGAN, Mandy-PERNICE, Regina. 2008. Staying or Returning: Pre-Migration Influences on the Migration Process of German Migrants to New Zealand. Journal of Community and Applied Social Psychology 18: 282-298.

CAROL, Sarah. 2013. Intermarriage Attitudes among Minority and Majority Groups in Western Europe: The Role of Attachment to the Religious In-Group. International Migration 51: 67-83.

DEMIRALP, Seda. 2012. White Turks, Black Turks? Fault Lines beyond Islamism versus Secularism. Third World Quarterly 33(3): 511-524.

DRIBE, Martin-LUNDH, Christer. 2008. Intermarriage and Immigrant Integration in Sweden: an Explanatory Analysis. Acta Sociologica 51(4): 329-354.

2011. Cultural Dissimilarity and Intermarriage: a Longitudinal Study of Immigrants in Sweden 1990-2005. International Migration Review 45(2): 297324.

FURTADO, Delia-THEODOROPOULOS, Nikolaos. 2008. Interethnic Marriage: a Choice between Ethnic and Educational Similarities. IZA Discussion Papers 3448 .

GARRIDO, Angeles Arjona-OLMOS, Juan Carlos Checa. 2014. The Marriage Market in Spain. Analysis of the Structure of Opportunity in Mixed Marriage. Sociológia 4(3): 300-319.

GASPAR, Sofia. 2009. Mixed Marriages between European Free Movers. CIES e-Working Papers.

KALMIJN, Matthijs. 1991. Shifting Boundaries: Trends in Religious and Educational Homogamy. American Sociological Review 56: 786-800. 1998. Intermarriage and Homogamy: Causes, Patterns, Trends. Annual Review of Sociology 24: 395-421.

KASTROYANO, Riva. 2002. Negotiating Identities: States and Immigrants in France and Germany. Princeton University Press. 
KAYA, Ayhan. 2012. Turkey as an Emerging Destination Country for Immigration: Challenges and Prospects for the Future in Europe, Turkey and the Mediterranean. Bertelsmann Stiftung, 85-95.

KLEIN, Thomas. 2001. Intermarriages between Germans and Foreigners in Germany. Journal of Comparative Family Studies 32(3): 325-346.

LUCASSEN, Leo-LAARMAN, Charlotte. 2009 Immigration, Intermarriage and the Changing Face of Europe in the Post War Period. History of the Family 14: $52-68$.

LUCIANA, Silva C.-CAMPBELL, Kelly-WRIGHT, David W. 2012. Intercultural Relationships: Entry, Adjustment, and Cultural Negotiations. Journal of Comparative Family Studies 43(6): 857-870.

MAI, Nicola-KING, Russell. 2009. Introduction. Love, Sexuality and Migration: Mapping the Issue(s). Mobilities 4(3): 295-307.

MAHLER, Sarah J.-PESSA, Patricia, R. 2006. Gender Matters: Ethnographers Bring Gender from the Periphery toward the Core of Migration Studies. International Migration Review 40(1): 28-63.

MASON, Jennifer. 2002. Qualitative Researching. SAGE, London.

McPHERSON, Miller-SMITH-LOVIN, Lyn-COOK, James M. 2001. Birds of a Feather: Homophily in Social Networks. Annual Review of Sociology 27: 415444.

MENG, Xin-GREGORY, Robert G. 2005. Intermarriage and the Economic Assimilation of Immigrants. Journal of Labor Economics 23(1): 135-175.

MUNNIKSMA, Anke-FLACHE, Andreas-VERKUYTEN, Maykel-VEENSTRA, Ren. 2012. Parental Acceptance of Children's Intimate Ethnic Outgroup Relations: the Role of Culture, Status, and Family Reputation. International Journal of Intercultural Relations 36: 575-585.

MUTTARAK, Raya-HEATH, Anthony. 2010. Who Intermarries in Britain? Explaining Ethnic Diversity in Intermarriage Patterns. The British Journal of Sociology 61(2): 275-305.

QIAN, Zhenchao-LICHTER, Daniel T. 2007. Social Boundaries and Marital Assimilation: Interpreting Trends in Racial and Ethnic Intermarriage. American Sociological Review 72: 68-94.

ROER-STRIER, Dorit-BEN EZRA, Dina. 2008. Intermarriages between Western Women and Palestinian Men: Multidirectional Adaptation Processes. Journal of Marriage and Family 68: 41-55.

SAFDAR, Saba-LAY, Clarry-STRUTHERS, Ward. 2003. The Process of Acculturation and Basic Goals: Testing a Multidimensional Individual Difference Acculturation Model with Iranian Immigrants in Canada. Applied Psychology: an International Review 52(4): 555-579. 
SAM, David L.-BERRY, John W. 2010. Acculturation: When Individuals and Groups of Different Cultural Backgrounds Meet. Perspectives on Psychological Science 5(4): 472-481.

SCOTT, Sam-CARTLEDGE, Kim H. 2009. Migrant Assimilation in Europe: a Transnational Family Affair. International Migration Review 43: 60-89.

SMART Carol-SHIPMAN, Beccy. 2004. Visions in Monochrome: Families, Marriage and the Individualization Thesis. The British Journal of Sociology 55(4): 491-509.

SONG, Miri. 2009. Is Intermarriage a Good Indicator of Integration? Journal of Ethnic and Migration Studies 35: 331-348.

2010. What Happens after Segmented Assimilation? An Exploration of Intermarriage and 'Mixed Race' Young People in Britain. Ethnic and Racial Studies 33: 1194-1213.

TARTAKOVSKY, Eugene. 2012. Factors Affecting Immigrants' Acculturation Intentions: a Theoretical Model and its Assessment among Adolescent Immigrants from Russia and Ukraine in Israel. International Journal of Intercultural Relations 36: 83-99.

TOLAY, Juliette. 2012. Discovering Immigration to Turkey: the Emergence of a Dynamic Field. International Migration 53(6): 1-17.

ÜLKER, Erol. 2007. Assimilation of the Muslim Communities in the First Decade of the Turkish Republic (1923-1934). European Journal of Turkish Studies (online).

WALTER G., Stephan-COOKIE WHITE, Stephan. 2000. An Integrated Threat Theory of Prejudice. In: S. Oskamp (ed.), Reducing Prejudice and Discrimination. Psychology Press. Claremont Symposium on Applied Social Psychology Series, 23-46. 